\title{
System Dynamics Approach for the Impacts of FINEX Technology and Carbon Taxes on Steel Demand: Case Study of the POSCO
}

\author{
Suk-Jae Jeong, \\ 1 School of Business, Kwangwoon University, 20, Gwangun-ro, Nowon-gu, Seoul, South Korea, 139-701 \\ \# Corresponding Author / E-mail: sjjeong@kw.ac.kr, TEL: +82-2-940-5294, FAX: +82-2-940-8181
}

KEYWORDS: Iron and steel industry, System dynamics, FINEX technology, Carbon tax

\begin{abstract}
The steel industry accounts for the largest share, approximately 27 percent, of global carbon dioxide emissions from the manufacturing sector. Changes in material and energy use, and emissions profiles of the iron and steel manufacturing are the result of complex interrelationships between technological and economic drivers. A better understanding of these changes require special attention paid to the time dependent consequences that technology and economic influences contribute to the choice of inputs and their associated outputs. We assess the impact that climate-change policies may have on energy use and carbon emissions in the Korean iron and steel industry. We then present models of the iron and steel industry's energy and product flow of POSCO corporation, with respect to environmental regulations by using the system dynamics (SD). Time series data and engineering information are combined to specify changes in technologies, fuel mix, and production processes. Various scenarios are used to analyze the consequences of climate change on the iron and steel industry. The results of these studies show strategies to prevent environmental changes are devised from various perspectives to minimize the risks associated with future uncertainties, all in an effort to be conducive to the sustainable development of the energy-intensive industry.
\end{abstract}

Manuscript received: August 21, 2014 / Revised: November 4, 2014 / Accepted: November 10, 2014

\section{Introduction}

Iron and steel manufacturing is one of the most energy-intensive industries worldwide. In addition, use of coal as the primary fuel for iron and steel production means that iron and steel production has among the highest carbon dioxide $\left(\mathrm{CO}_{2}\right)$ emissions of any industry. ${ }^{13}$ According to the International Energy Agency (IEA), the iron and steel industry accounts for the largest share- approximately 27 percent - of $\mathrm{CO}_{2}$ emission from the global manufacturing sector (IEA 2007). ${ }^{3}$

Korea's iron and steel industry was ranked $6^{\text {th }}$ in the world on the basis of the production of crude steel and produced 43.1million tons in 2008. In addition, the Korean company POSCO, is ranked first in the world on the basis of crude steel production. The production of crude steel in POSCO in 2010 was increased by $17.2 \%$ in comparison with the 36.8 million tons in 2005 , and by $1.3 \%$ compared to 2005 production levels (42.6 million tons).

The main facility of POSCO's iron and steel industry is an iron producing facility, which has a total of 11 blast furnaces with a capacity of 26,010 thousand tons/year. The steel-making facilities consist of 12 basic oxygen furnaces with a capacity of 26,180 thousand tons/year and electric arc furnaces with a capacity of 23,475 thousand tons/year. The proportion of steel made from electric arc furnaces to the total steel production was $47.3 \%$ in 2010 , and this fraction is continuously increasing. In addition, a continuous caster with a 47,760 thousand tons-per-year capacity is operational. Nearly all iron and steel facilities in POSCO are considered to be world class in terms of energy efficiency. The products from this industry include plates, hot rolled coils, and stainless steel products, and the various production lines can produce many kinds of products. Steel companies continued to invest in new systems to improve operations and yield, and to reduce carbon dioxide (Steel Trade Today, 2008). The new FINEX iron-making process, developed by POSCO,${ }^{7}$ uses both fine coal and fine iron ore, making it more cost effective than the similar Corex process, and emission are almost $80 \%$ less than those of the blast furnance process (Ramstad, 2008). It is, thus, important to compare the iron and steel industry in Korea with the other Korean industries for GHG emissions 
control, since the huge energy consumption of the steel industry is the primary source of its carbon dioxide emissions. Therefore, this paper evaluates the reduction potential of carbon dioxide emissions in POSCO using a new technology, FINEX, as well as the application of carbon taxes. This study emphasizes evaluation of the competitiveness of new technologies that replace blast furnaces using FINEX, and analyzes the ripple caused by imposing carbon taxes.

A few studies have analyzed $\mathrm{CO}_{2}$ emissions reduction potentials within the steel industry. Wang et al. (2007) ${ }^{11}$ used LEAP software to assess the $\mathrm{CO}_{2}$ abatement potential of China's steel industry through three different $\mathrm{CO}_{2}$ emissions scenarios, from 2000 to 2030. Kim and Worrell (2002) $)^{5}$ presented an in-depth decomposition analysis of trends in $\mathrm{CO}_{2}$ emissions with respect to iron and steel industry physical indicators. Detailed decomposition analyses are available for the iron and steel industries in seven countries, including Brazil, China, and India (developing countries), as well as Mexico and South Korea (newly industrialized countries), and the United States (industrialized country. Hidalgo et al. $(2005)^{2}$ designed a simulation model to analyze the evolution of the industry from 1997 to 2030, focusing on steel production, demand, trade, energy consumption, $\mathrm{CO}_{2}$ emission, technology dynamics, and retrofitting options. Ruth and Amato (2002) ${ }^{8}$ investigated implications of changes in the cost of carbon for output, energy use and energy emission profiles of the iron and steel industry, and compare the results for different climate changes and technology policies. Zhang et al. (2012) ${ }^{14}$ designed to identify the determinants that drive or impede the $\mathrm{CO}_{2}$ reduction practices of Chinese IS companies, and assessed the relationship between the practices and performance using the conceptual modeling that consists of 7 hypotheses.

This paper models the Korean steel industry's energy and product flow with regard to environmental regulations by using a system dynamics (SD) simulation. In this regard, through a developed scenario, the ramifications that climate change conventions would bring to the steel industry are analyzed. Based on the study results, strategies to prevent environmental changes are contemplated with respect to various perspectives that contribute to minimize the risks concerning the uncertain future of the sustainability of the Korean steel industry.

\section{Current and Alternative Iron-Making Technologies}

\subsection{Blast Furnace}

The purpose of a blast furnace (BF) is to chemically and physically convert iron oxides into liquid iron called "hot metal". ${ }^{9}$ The BF is the most common today. In 2010, BF production accounted for approximately 65 percent of the steel manufactured worldwide. The BF is a huge, steel stack lined with refractory brick, where iron ore, coke and limestone are dumped into the top, and preheated air is blown into the bottom. According to the AISI report (2010), ${ }^{1}$ the BF is the most energy-intensive step in the steel making process, generating large quantities of $\mathrm{CO}_{2}$.

\subsection{FINEX}

In the FINEX process the reduction shaft of the COREX is replaced by a series of fluidized beds. This enables the FINEX process to use

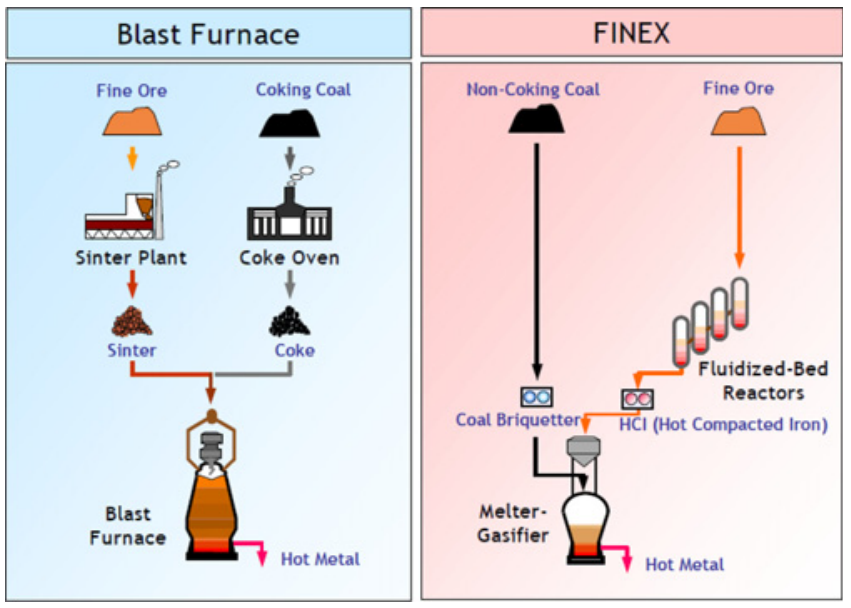

Fig. 1 Blast Furnace vs. FINEX

fine ores instead of lump ore or pellets. As a result the process requires neither coke making nor ore agglomeration (Fig. 3). Briquetting of the pre-reduced ore and the coal, pulverized coal injection and controlled charging of the melter / gasifier have improved the fuel rate of the process compared to the original Corex process. The process includes a $\mathrm{CO}_{2}$ scrubber. The isolated $\mathrm{CO}_{2}$ can be stored geologically if such a storage is available. With geological storage a $\mathrm{CO}_{2}$ emission reduction of $45 \%$ is achieved. POSCO has operated a $1.5 \mathrm{Mt} / \mathrm{y}$ plant for several years and has recently ordered the engineering and supply of proprietary equipment for a $2.0 \mathrm{Mt} / \mathrm{y}$ plant to be constructed at Pohang.

\section{System Dynamic Model}

\subsection{Production Route of Main Products from the Iron and Steel Industry}

Iron and steel production generates $\mathrm{CO}_{2}$ emissions as 1) process emission, in which raw materials and combustion both may contribute to $\mathrm{CO}_{2}$ emissions; 2) emissions from combustion source alone; and 3) indirect emissions from consumption of electricity. (U.S EPA 2010).

First, we described the aggregated materials and product flows of the iron and steel industry. Fig. 2 shows the production routes of the main products of a major Korean iron and steel company, and is the reference used for SD model, which was designed by analyzing all of the material and product flows for model operation.

\subsection{System Dynamics Approach}

In this paper, we have adopted the SD methodology for the assessment and mitigation of $\mathrm{CO}_{2}$ emissions from POSCO. The software package 'Vensim', which is available for SD analysis, was used in developing a model for the steel sector.

$\mathrm{SD}$ is a computer-aided approach for analyzing and solving complex problems with an emphasis on policy analysis and design. In management and social systems, policy-makers and researchers have extensively used the SD methodology for policy experiments. A detailed description of the SD methodology is given in Sterman. ${ }^{10}$ The SD approach has been applied to a number of studies related to the environment: including environmental impact assessment analysis, solid waste management, ${ }^{4}$ analysis of greenhouse gas emissions and 


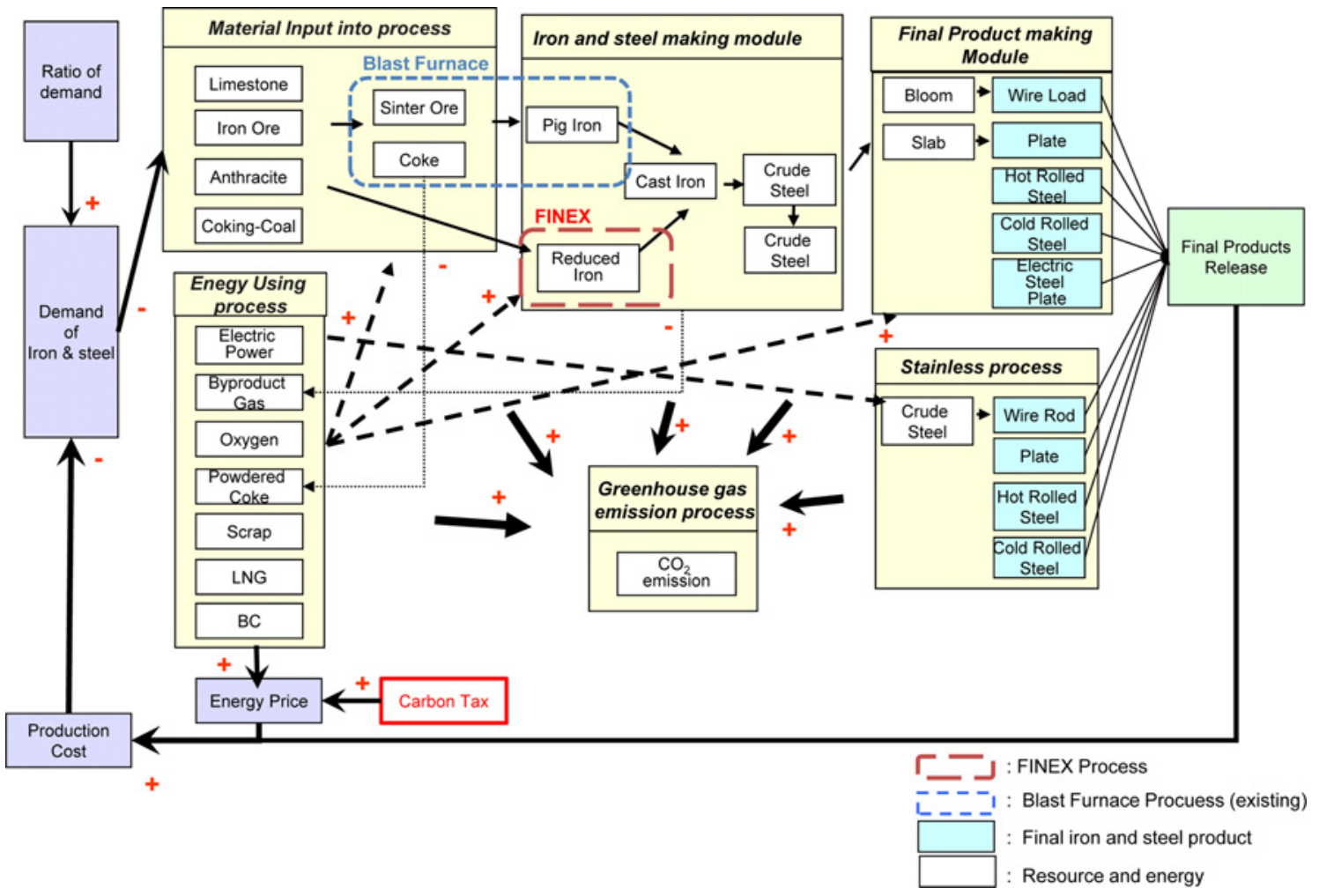

Fig. 2 Aggregated materials / product flows of POSCO

global warming, ${ }^{12}$ environmental planning and management, ${ }^{6}$ and many other situations.

The SD model is developed by establishing a causal-loop relationship between the components associated with the model in the form of a causal-loop diagram. Then a flow diagram is constructed and dynamo equations are added to the model. In the SD model, the simulations are essentially time-step simulations. The model takes a number of simulation steps along the time axis. The dynamics of the system are represented by $d N(t) / d t=k N(t)$ which has a solution $N(t)=N_{0} \quad \exp t(k t)$. Here, $N_{0}$ is the initial value of the system variable, $k$ is a rate constant (which affects the state of the system), and $t$ is the simulation time. For the simulations to be run for the first time, initial values of the system variables are needed.

\subsection{Causal-Loop and Flow Diagram for the Iron and Steel Making}

To investigate the implications of climate change policies for carbon emissions by POSCO, we developed a causal-loop diagram that uses econometric and environmental forecasting techniques in combination with a SD approach to establish iron and steel industry-demand, production, contraction of the process within industrial sectors, their associated energy and resource usage, and their $\mathrm{CO}_{2}$ emissions.

In this study, the production module includes an energy and resource input module based on iron and steel demand, a sintering and coking process module, an iron and steel making process module, a steam supply and power generation process module, a continuous casting and rolling process module, a stainless process module, and a greenhouse gas emission process module (Fig. 3). Each of the modules is described in more detail using the SD model. Parameters that guide the relationships between variables within or between sub-modules are

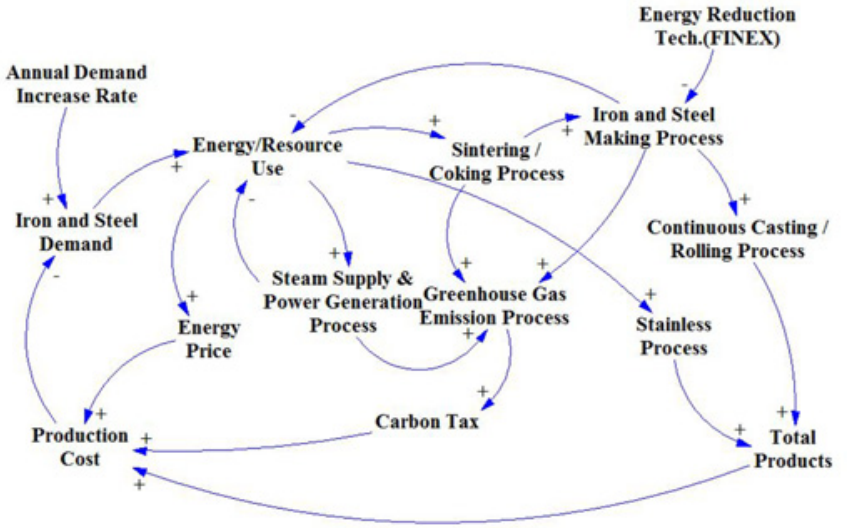

Fig. 3 Aggregated materials / product flows of POSCO

either econometrically estimated from the time series data or based on engineering information.

As shown in Fig. 3, the mutual interactions associated with iron and steel production and the related $\mathrm{CO}_{2}$ emission are expressed in energy units and the product flow within the production module. Dynamics of the model are determined by the feedback loops of the causal loop diagram. Each arrow of the causal loop diagram indicates the influence of one element on the other. The influence is considered positive $(+)$ if an increase in one element causes an increase in another or negative $(-)$ in the opposite case.

A flow diagram is useful for showing the physical components and information flows of the relationship between the two variables that are connected in the SD model. Fig. 4-8 provides the details of the flow diagram developed for analyzing the iron and steel sector. Intricacies of the mutually interacting processes are also delineated in the flow 
diagram. Once the simulation is complete, at the end of each step, the system is refreshed to give the results from the previous simulation step. The rate variables are represented by constant values. The information from the level variables to the rate variables is transformed by a third variable called the auxiliary variable. A constant, which does not vary over the run period of the simulation, is defined by an initial value throughout the simulation. There is a switch control in which the initial values of constants, auxiliaries, and levels can be changed and a selection can be made between alternative strategies. To avoid confusion in the diagram, repeated variables are represented in the form of snapshot variables. The flow diagram is divided into five submodules and the modeling details of five subsystems are described in the following sub-modules.

\subsubsection{Iron and Steel Demand Generation}

The module for iron and steel demand is shown in Fig. 4. Iron and steel demand is determined according to the demand rate increase and production cost. The production cost change rate is calculated from change rates between the current and the previous year's production costs. Resources, energy purchasing price, and the carbon tax determine the production cost. The purchasing price of resources is affected by the amount of scrap iron consumed, the price rate of non-coking coal, and iron ore. The energy purchasing price is determined by ore, LNG, crude oil, electric power consumption; the increasing rates of energy prices are also assumed to be constants, as they do not vary over the run period of the simulation. The carbon tax is calculated by multiplying the carbon dioxide emissions of each process by the carbon tax per unit.

The equations for the main variables in this module are as follows:

- Accumulative Energy Price Ascent Rate = Energy Price Ascent Rate*Accumulative Energy Price Ascent Rate

- Energy Purchasing Price $=($ Amount of Fuel Coal Used*1.6*80+ Amount of Crude Oil Used* 2.8*60 + Amount of LNG Used*6.7*80 + Amount of Electric Power Used*17.16) *(Accumulative Energy Price Ascent Rate +1$)^{*} 1200 / 1000$

- Amount of Demand Change $=$ Steel Demand*(Steel Industry Demand Increase Rate-(Production Cost Change Rate -1$)^{*} 0.8$ )

- Current Production Cost $=$ Energy Purchasing Price + Sum of Carbon Tax + Raw Materials Purchasing Price

- Amount of Demand Change $=$ Steel Demand*(Steel Industry Demand Increase Rate - (Production Cost Change Rate -1$) * 0.8$ )

- Steel Demand = INTEGRAL (Amount of Demand Change), initial value $=2.23488 \mathrm{e}+007$

\subsubsection{Materials Input}

A detailed module for the determination of the amount of the material input is explained in Fig. 5. Coking coal, iron ore, and anthracite consumption are determined by the cast iron production volume. The model shows that the introduction of the FINEX process reduces the ore purchasing price by $20 \%$, and decreases the coking coal consumption by $15 \% . \mathrm{CO}_{2}$ emissions are modeled to decrease by $15 \%$.

- Change of Coking Coal Purchasing Price $=$ (Using Amount of Coking Coal + Using Amount of Coking coal in FINEX process)*120.2

- Change of Iron Ore Purchasing Price $=$ Using Amount of Iron Ore*36.2 + Using amount of Iron ore in FINEX process*28.96

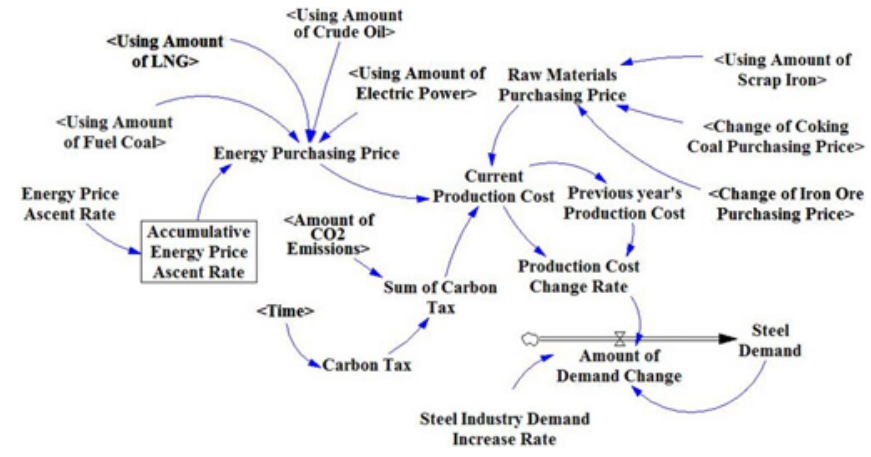

Fig. 4 SD module for iron and steel demand

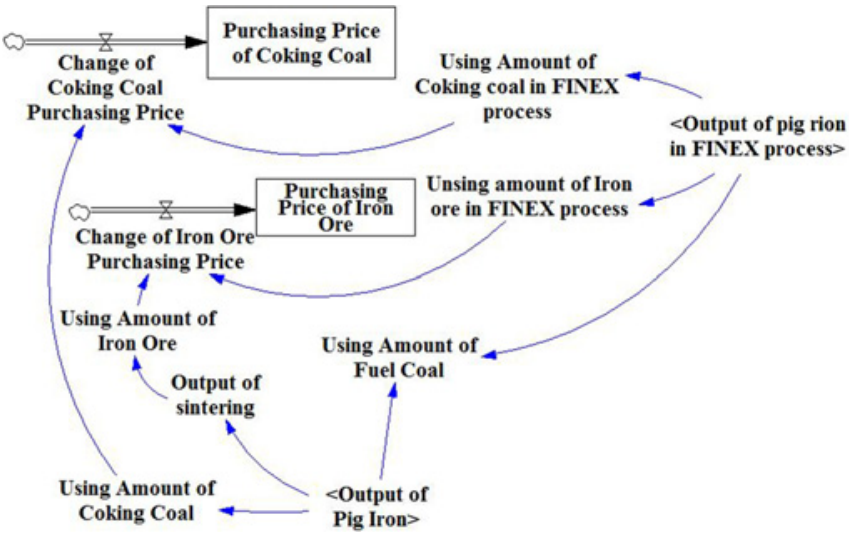

Fig. 5 SD module for material input

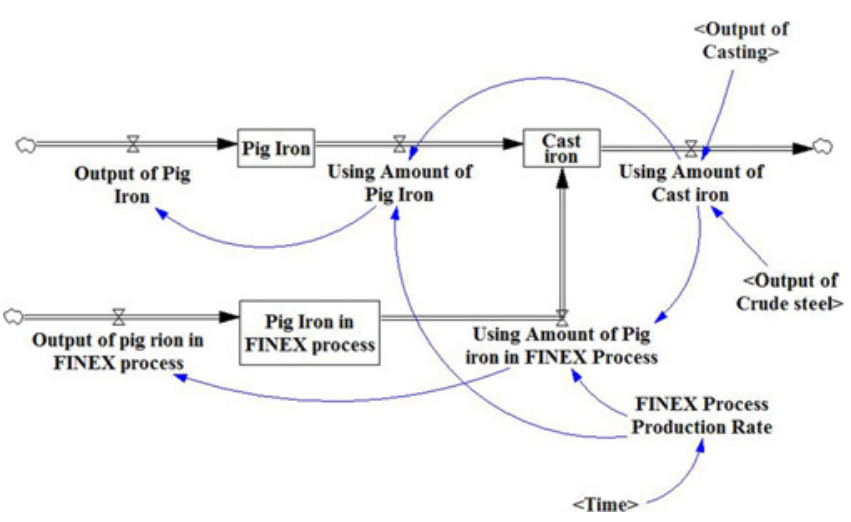

Fig. $6 \mathrm{SD}$ model for iron and steel making module

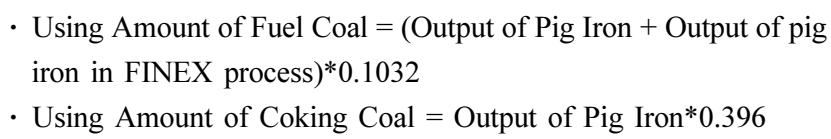

\subsubsection{Iron and Steel Making}

In Fig. 6, cast iron consumption is modeled considering both the existing slimming lines process and the newly introduced FINEX process. The FINEX process, which is currently in its nascent phase, is predicted to completely replace the existing slimming lines process by 2016 , at a rate of $5 \%$ from 2010 to 2013 , and at $10 \%$ after 2013 . This is applied to the TECH scenario when analyzing the simulation results.

- Amount of Pig Iron Used = Amount of Cast Iron Used*(1 FINEX Process Production Rate)

- Amount of Cast Iron Used = Output of Casting + Output of Blister Steel 


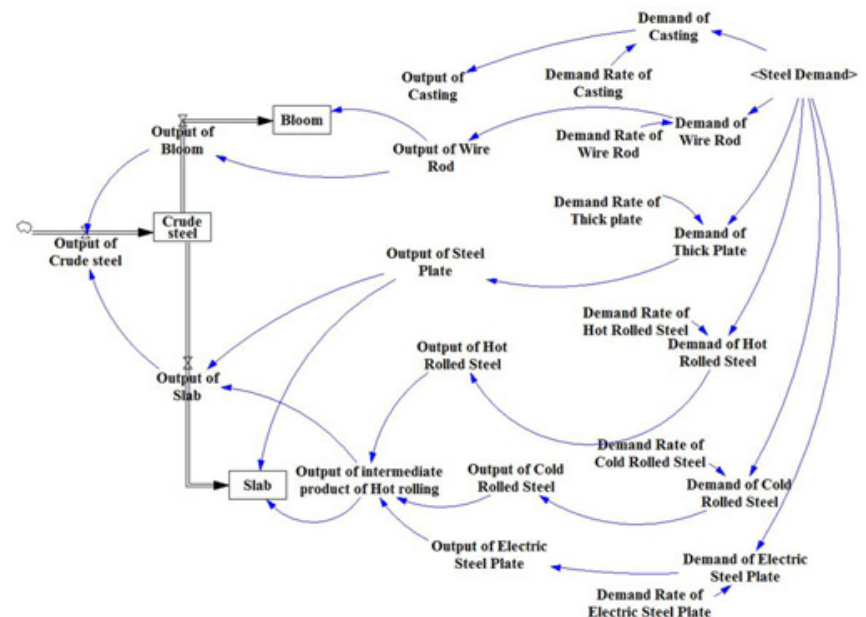

Fig. 7 SD model for final product production

- FINEX Process Production Rate $=$ if then else $($ Time $<2010,0$, if then else(Time $<2014$, (Time -2010$\left.)^{*} 0.05\right)$, (Time -2010$)^{*} 0.1$ )

- Amount of FINEX Process' Pig Iron Used = Amount of Cast Iron Used*FINEX Process Production Rate

- Cast Iron = INTEGRAL(Amount of Pig Iron Used + Amount of Pig Iron Used in the FINEX Process- Amount of Cast Iron Used)

\subsubsection{Production Module for Final Products}

The final product demands considered in this study are casting, wire rods, steel plates, hot rolled steel, cold rolled steel, and electric steel plates, as seen in Fig 8. The proportion of each product composing the total steel demand are treated as a fixed cost during the years 2000 2030.

The outputs for blooms, slabs, and billets, all of which require crude steel to be produced, are determined by the output of each final product.

The equations of SD diagram in this module are as follows:

- Demand of Thick Plate $=$ Steel Demand $*$ Demand Rate of Thick plate

- Slab = INTEGRAL (Output of Slab-Output of Intermediate Product of Hot Rolling - Output of Thick Plate)

- Output of Slab $=$ Output of Thick Plate + Output of Intermediate Product of Hot rolling

- Crude Steel $=$ INTEGRAL (Output of Crude steel-Output of Bloom-Output of Slab)

- Output of Crude Steel $=$ Output of Bloom + Output of Slab

\subsection{5 $\mathrm{CO}_{2}$ Emissions Module}

Fig. 8 illustrates the concrete module for carbon dioxide emissions. Crude oil, coking coal, LNG, and cast iron determine the $\mathrm{CO}_{2}$ emissions, and the introduction of the FINEX process is considered in its entirety.

- Amount of $\mathrm{CO}_{2}$ Emissions $=$ Amount of Fuel Coal Used $* 0.0425 * 25.8+$ Amount of Coking Coal Used $* 0.0425 * 25.8$

+ Amount of Crude Oil Used*0.0425*21.2 + Amount of LNG Used*0.0425*15.8 + Amount of Coking Coal Used in the FINEX Process*0.0425*25.8 + (Output of Pig Iron + Output of Pig Iron in the FINEX process)*0.0005*109+ (Amount of Electric Power

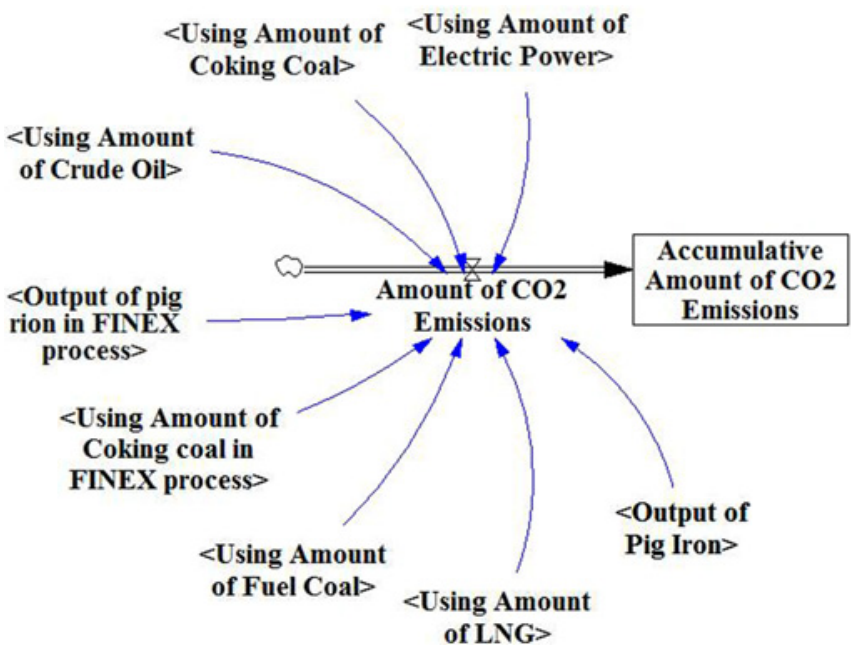

Fig. $8 \mathrm{SD}$ model for $\mathrm{CO}_{2}$ emission

Table 1 Energy and fuel price

Unit: energy $(\$ / G J)$, fuel(\$/Ton)

\begin{tabular}{cccc}
\hline Energy/Fuel & Price & Energy/Fuel & Price \\
\hline Coking coal & 2.0 & Thermal coal & 1.6 \\
\hline Anthracite coal & 1.1 & Crude oil & 2.8 \\
\hline LNG & 6.7 & Electric power & 17.16 \\
\hline Scrap iron & 16.0 & & \\
\hline
\end{tabular}

Source: Korea Institute of Energy Research Report on August 2006

Table $2 \mathrm{CO}_{2}$ emission factors

Unit: $\mathrm{kg} \mathrm{C} / \mathrm{GJ}$

\begin{tabular}{cccc}
\hline Energy source & $\begin{array}{c}\text { Emissions } \\
\text { coefficient }\end{array}$ & Energy source & $\begin{array}{c}\text { Emissions } \\
\text { coefficient }\end{array}$ \\
\hline Coking coal & 25.8 & Thermal coal & 25.8 \\
\hline Crude oil & 21.2 & Electric power & 31.4 \\
\hline LNG & 15.8 & &
\end{tabular}

Source: Korea Institute of Energy Research Report on August 2006

Used $) * 3.383 * 31.4$

- Accumulative Amount of $\mathrm{CO}_{2}$ Emissions = INTEGRAL (Amount of $\mathrm{CO}_{2}$ Emissions)

\section{Simulation Assumptions and Scenarios}

\subsection{Simulation Assumptions}

In this study, the simulation's base year for estimation was 2005 . Basic assumptions of the model used for simulation analysis are as follows: production equipment volume is assumed to satisfy demand, the production time for each product is considered to be the same for all products, and inventory is not included.

As for steel demand, the production cost of steel products and the demand increase rate are the decisive factors; by analyzing the data from past trends, the demand increase rate is set to increase by $5 \%$ each year. The production cost in this model is influenced by raw materials, energy purchasing cost, and the carbon tax. The purchasing cost of raw materials is confined to ore, coking-coal, and scrap iron. Energy purchasing cost included thermal coal, LNG, electric power, and crude oil. Constant numbers that used in equations of SD model are given in Tables 1 and 2 


\subsection{Scenarios for Simulation Analysis}

The following three major scenarios were used for simulation analysis. This section describes the basic contents for each scenario.

Business as usual (BAU) scenario: This is a scenario based on the assumption that the current trend in steel demand from the overall assessment period of 2014 to 2030 will continue.

This scenario does not adopt any policy or investment regarding the Convention on Climate Change. That is, over the course of time, the demand for steel and the $\mathrm{CO}_{2}$ emissions variance are predicted to increase in accordance with data from past trends. Furthermore, the raw materials consumption for each product is proportionate to the composition ratio of the product.

However, the efficiency of technology improvement and changing the ratio of material supply are considered by means of the Autonomous Efficiency Improvement (AEEI), and the major AEEI reflecting ideas are as follows.

(1) Pulverized coal injection (PCI) of a blast furnace will continuously extend up to $150 \mathrm{~kg} /$ ton irons until the year 2030 .

(2) Improvement of the self-generation efficiency using by-product gas will increase $30 \%$ in 2020 and $35 \%$ in 2030 .

(3) The material losses from the rolling process will be low, approximately $5 \%$ until 2030 .

TECH Scenario: This scenario was introduced to show the potential $\mathrm{CO}_{2}$ emissions by replacing the existing methods with the FINEX process, which is an innovative, next generation iron making technology developed by POSCO, the representative iron and steel making company of Korea. By using the FINEX process, molten iron is produced directly using iron ore fines and non-coking coal rather than processing through sintering and coke making, which is essential to traditional blast furnace methods. Because the preliminary processing of raw materials is eliminated, the construction of the FINEX plant costs less to build than a blast furnace facility of the same scale. Furthermore, a $10-15 \%$ reduction in production costs is expected through cheaper raw materials, reduction of facility costs, pollutant exhaustion, maintenance staff, and production time. In addition, it is eco-friendly in that it produces less $\mathrm{CO}_{2}$ than traditional methods. The FINEX process ends its technology development by the end of 2006, and partial introduction begins in 2007. We assume that replacement of existing blast furnaces will take place at a rate of $3 \%$ until 2010, and by $5 \%$ every year after 2011 .

Carbon Tax (CTAX) Scenario: This scenario was designed to assess the reduction potential of $\mathrm{CO}_{2}$ emission according to various carbon tax policies.

(1) CTAX-30 (carbon tax 30 USD/TC): a carbon tax of 30 US dollars will be applied per ton of $\mathrm{CO}_{2}$ emission

(2) CTAX-60 (carbon tax $60 \mathrm{USD} / \mathrm{TC}$ ): a carbon tax of $60 \mathrm{US}$ dollars

(3) CTAX-90 (carbon tax 90 USD/TC): a carbon tax of 90 US dollars

Combination of TECH Scenario and CTAX Scenario: This scenario was designed to assess the synergy effects when both the TECH and the carbon taxes scenarios are applied altogether.
Table 3 Mean absolute percentage error for selected variables

Unit: 1000 TOE

\begin{tabular}{cccc}
\hline Variable & Actual value & Estimation value & MAPE(\%) \\
\hline $\begin{array}{c}\text { Thermal coal } \\
\text { Consumption }\end{array}$ & 2,550 & 2,608 & 2.20 \\
\hline $\begin{array}{c}\text { LNG } \\
\text { consumption }\end{array}$ & 747 & 759 & 1.61 \\
\hline $\begin{array}{c}\text { Coking-coal } \\
\text { consumption }\end{array}$ & 9,770 & 10,000 & 2.35 \\
\hline $\begin{array}{c}\text { Electric Power } \\
\text { consumption }\end{array}$ & 2,723 & 2,784 & 2.24 \\
\hline
\end{tabular}

Source of actual value: Reports of Korean Institute of Energy Research (2010-2012)

(1) TECH-30 (the introduction of FINEX and the imposition of carbon tax $30 \mathrm{USD} / \mathrm{TC})$

(2) TECH-60 (the introduction of FINEX and the imposition of carbon tax $60 \mathrm{USD} / \mathrm{TC})$

(3) TECH-90 (the introduction of FINEX and the imposition of carbon tax $90 \mathrm{USD} / \mathrm{TC})$

\section{Model Validation}

In order to evaluate robustness, or the model stability and predictability over a certain period of time, back-casting analysis is performed from 2010 to 2013. By comparing the simulation results and the actual data for the predictability of the model, criteria such as MAPE (Mean Absolute Percentage Errors) are used in the selection of a model. A MAPE estimate can be calculated by the equation.

$$
\operatorname{MAPE}(\%)=\frac{\sum_{i}^{N} \frac{\left|y_{i}^{p}-y_{i}^{A}\right|}{y_{i}^{A}}}{N} \times 100
$$

Where, $y_{i}^{p}$ is the $i^{\text {th }}$ endogenous variable predicted by the model solution during the sample period, and $y_{i}^{A}$ is the actual value of the $i^{t h}$ endogenous variable. $N$ signifies the observation value. A MAPE below $3 \%$ means that predictability is considered to be excellent, if it is less than $5 \%$ then it is good, and it is generally considered to be unacceptable for values above $8 \%$. In Table 3 the corresponding MAPE values for some selected variables are given. These results indicate the robustness of the model.

\section{Simulation Results and Discussion}

\subsection{Energy Consumption}

The energy consumption of the BAU scenario is provided in Table 4. In terms of the weight of each energy resource, the proportion of coking coal continues to decline, and electricity and steam coal accounts for a larger proportion of the total energy consumption. This change is attributed to the increase of steam coal injection in the blast furnace.

Fig. 9 shows the results for energy consumption under the eight scenarios from 2005 to 2030. The energy consumption of BAU ranged from 754.90(2010) PJ to 780.71 PJ (2030). The energy consumption of 
Table 4 Energy consumption of BAU scenario

(unit: $1,000 \mathrm{TOE}(\mathrm{PJ})$ )

\begin{tabular}{ccccccc}
\hline & 2005 & 2010 & 2015 & 2020 & 2025 & 2030 \\
\hline Steam & 2,870 & 3,074 & 3,254 & 3,539 & 3,771 & 4,055 \\
coal & $(120)$ & $(129)$ & $(136)$ & $(148)$ & $(158)$ & $(170)$ \\
\hline Coking & 10,033 & 9,918 & 9,684 & 9,425 & 9,333 & 9,342 \\
coal & $(420)$ & $(415)$ & $(405)$ & $(394)$ & $(390)$ & $(391)$ \\
\hline Anthracite & 329 & 332 & 332 & 342 & 347 & 355 \\
coal & $(14)$ & $(14)$ & $(14)$ & $(14)$ & $(15)$ & $(15)$ \\
\hline \multirow{2}{*}{ Crude oil } & 1,222 & 1,186 & 1,154 & 1,108 & 1,071 & 1,035 \\
& $(51)$ & $(50)$ & $(48)$ & $(46)$ & $(45)$ & $(43)$ \\
\hline \multirow{2}{*}{ LNG } & 828 & 904 & 973 & 1,069 & 1,133 & 1,204 \\
& $(35)$ & $(38)$ & $(41)$ & $(45)$ & $(47)$ & $(50)$ \\
\hline \multirow{2}{*}{ Electric } & 2,724 & 2,750 & 2,864 & 2,935 & 2,969 & 3,040 \\
power & $(114)$ & $(115)$ & $(120)$ & $(123)$ & $(124)$ & $(127)$ \\
\hline \multirow{2}{*}{ TOTAL } & 17,937 & 18,042 & 18,092 & 18,174 & 18,317 & 18,659 \\
& $(750)$ & $(755)$ & $(757)$ & $(760)$ & $(766)$ & $(781)$
\end{tabular}

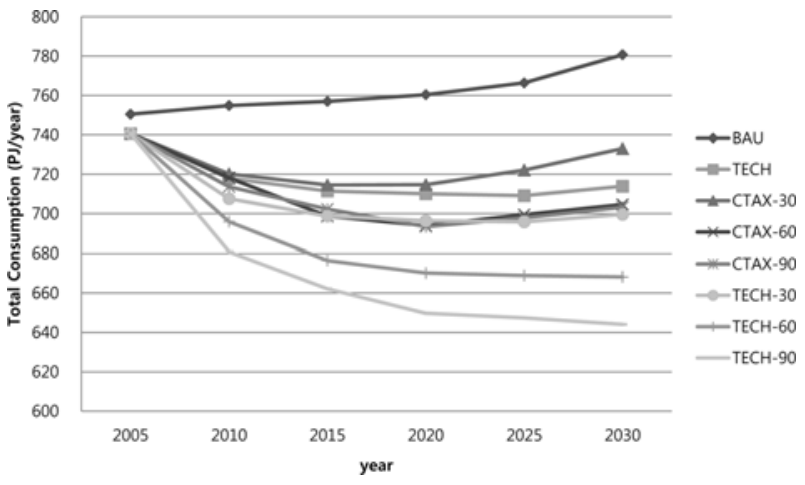

Fig. 9 Energy consumption forecast for different scenarios

TECH decreased by $4.89 \%$ in 2010 , and by $8.56 \%$ in 2030 , in comparison to the BAU scenario. This is likely a result of a reduction in the energy consumption by the sintering and coking processes in response to the yearly increase of the FINEX technology.

For the CTAX that considers the cost of carbon dioxide emissions in the model, there was no apparent change in energy consumption, especially comparing the $30 \mathrm{USD} / \mathrm{TC}$ and TECH cases. This means that present technologies, which belong to the BAU scenario, do not impact energy consumption in spite of the additional cost of $30 \mathrm{USD} /$ TC. In CTAX-60, energy consumption is decreased by $9.75 \%$ in 2030 , and for CTAX-90, it is decreased by $9.97 \%$ in 2030 in comparison with the BAU scenario. The TECH scenario shows a significant decrease of energy consumption compared with the 2005 value, which is prior to the introduction of the FINEX Technology. Energy consumption in the TECH scenario is only decreased by $1.32 \%$; however in 2030 , it drops by $8.56 \%$. When including the CTAX, the energy consumption significantly decreases relative to the BAU, but varies little from the TECH scenario. This indicates that even though the cost of carbon dioxide emission is imposed, this cost has minimal effect the total energy consumption. However, a combination of TECH and CTAX produces obvious effects, showing a significant decrease of energy consumption compared with the BAU, CTAX, and TECH scenarios. This illustrates that scenarios that apply both TECH and CTAX concurrently are a quite effective method to reduce energy consumption in the iron and steel industry.

Table 5 shows the energy consumption per ton of final products. In
Table 5 Energy consumption per unit production

Unit: GJ/ton

\begin{tabular}{ccccccc}
\hline & 2005 & 2010 & 2015 & 2020 & 2025 & 2030 \\
\hline BAU & 16.49 & 16.32 & 16.10 & 15.93 & 15.81 & 15.85 \\
\hline TECH & 16.28 & 15.57 & 15.22 & 14.97 & 14.90 & 14.88 \\
\hline CTAX-30 & 16.28 & 15.57 & 15.20 & 14.97 & 14.90 & 14.88 \\
\hline CTAX-60 & 16.28 & 15.53 & 14.86 & 14.54 & 14.43 & 14.31 \\
\hline CTAX-90 & 16.28 & 15.43 & 14.94 & 14.53 & 14.39 & 14.28 \\
\hline TECH-30 & 16.28 & 15.12 & 14.88 & 14.40 & 14.05 & 13.74 \\
\hline TECH-60 & 16.28 & 15.08 & 14.41 & 14.05 & 13.97 & 13.52 \\
\hline TECH-90 & 16.28 & 15.01 & 14.47 & 14.04 & 13.95 & 13.42 \\
\hline
\end{tabular}

Table 6 Material consumption per unit volume

Unit: GJ/ton

\begin{tabular}{|c|c|c|c|c|c|c|c|}
\hline Material & Scenarios & 2005 & 2010 & 2015 & 2020 & 2025 & 2030 \\
\hline \multirow{8}{*}{$\begin{array}{l}\text { Scrap } \\
\text { iron }\end{array}$} & BAU & 26.22 & 26.98 & 27.96 & 28.62 & 29.16 & 29.49 \\
\hline & TECH & 26.22 & 27.09 & 27.64 & 27.85 & 27.64 & 28.72 \\
\hline & CTAX-30 & 26.22 & 27.09 & 27.64 & 27.85 & 27.64 & 28.72 \\
\hline & CTAX-60 & 26.22 & 27.09 & 27.64 & 27.85 & 27.64 & 28.72 \\
\hline & CTAX-90 & 26.22 & 27.09 & 27.64 & 27.85 & 27.64 & 28.72 \\
\hline & TECH-30 & 26.22 & 27.15 & 27.47 & 27.47 & 26.87 & 28.34 \\
\hline & TECH-60 & 26.22 & 27.17 & 27.41 & 27.32 & 26.57 & 28.19 \\
\hline & TECH-90 & 26.22 & 27.18 & 27.38 & 27.24 & 26.42 & 28.12 \\
\hline \multirow{8}{*}{$\begin{array}{l}\text { Iron } \\
\text { ore }\end{array}$} & BAU & 34.27 & 34.60 & 34.49 & 34.82 & 35.25 & 36.12 \\
\hline & TECH & 34.27 & 34.06 & 34.49 & 34.82 & 35.25 & 35.69 \\
\hline & CTAX-30 & 34.27 & 34.06 & 34.49 & 34.82 & 35.25 & 35.69 \\
\hline & СТAX-60 & 34.27 & 34.06 & 34.49 & 34.60 & 34.93 & 35.36 \\
\hline & CTAX-90 & 34.27 & 33.73 & 34.16 & 34.60 & 35.04 & 35.47 \\
\hline & TECH-30 & 34.27 & 33.78 & 34.49 & 34.82 & 35.25 & 35.47 \\
\hline & TECH-60 & 34.27 & 33.68 & 34.49 & 34.67 & 35.02 & 35.15 \\
\hline & ТЕCH-90 & 34.27 & 33.27 & 34.20 & 34.62 & 35.06 & 35.10 \\
\hline \multirow{8}{*}{ Slag } & BAU & 14.36 & 14.47 & 14.47 & 14.58 & 14.80 & 15.23 \\
\hline & TECH & 14.36 & 14.25 & 14.47 & 14.58 & 14.80 & 15.02 \\
\hline & CTAX-30 & 14.36 & 14.25 & 14.47 & 14.58 & 14.80 & 15.02 \\
\hline & CTAX-60 & 14.36 & 14.25 & 14.36 & 13.93 & 13.82 & 14.04 \\
\hline & CTAX-90 & 14.36 & 13.38 & 13.60 & 13.60 & 13.71 & 13.82 \\
\hline & TECH-30 & 14.36 & 14.14 & 14.47 & 14.58 & 14.80 & 14.91 \\
\hline & TECH-60 & 14.36 & 14.10 & 14.39 & 14.12 & 14.11 & 14.18 \\
\hline & TECH-90 & 14.36 & 13.27 & 13.69 & 13.70 & 13.82 & 13.74 \\
\hline
\end{tabular}

the BAU case, this value steadily decreases from $16.32 \mathrm{GJ} /$ ton in 2010 , to $15.93 \mathrm{GJ} /$ ton in 2020 , and finally $15.85 \mathrm{GJ} /$ ton in 2030 . The TECH and CTAX-30 cases show the similar trends for the energy consumption per unit production. In the CTAX scenario, the energy consumption significantly decreases in relation to the BAU, but is not very different from the TECH scenario. This indicates that even though the cost of $\mathrm{CO} 2$ emission is imposed, the total energy consumption is not significantly affected.

In contrast, for the combination of CTAX and TECH, a significant decrease of energy consumption is evident compared with the values from 2005, which is before the introduction of FINEX and the imposition of the carbon tax.

\subsection{Material Consumption}

In the BAU case, scrap iron consumption increases from 26.22 million TC in 2005 to 29.49 million TC (see Table 6). The other scenarios all show a decrease in comparison with BAU, but the difference is not large. Iron ore consumption increases from 34.27 
Table $7 \mathrm{CO}_{2}$ emission by fuel for different scenario

\begin{tabular}{|c|c|c|c|c|c|c|c|}
\hline Scenarios & Fuel type & 2005 & 2010 & 2015 & 2020 & 2025 & 2030 \\
\hline \multirow{8}{*}{ BAU } & steam coal & 10,322 & 10,203 & 9,962 & 9,696 & 9,601 & 9,611 \\
\hline & coking coal & 2,092 & 2,241 & 2,372 & 2,580 & 2,749 & 2,955 \\
\hline & $\begin{array}{c}\text { anthracite } \\
\text { coal }\end{array}$ & 342 & 345 & 346 & 357 & 361 & 370 \\
\hline & crude oil & 1,056 & 1,024 & 996 & 957 & 925 & 894 \\
\hline & LNG & 539 & 589 & 634 & 696 & 737 & 784 \\
\hline & $\begin{array}{l}\text { electric } \\
\text { poser }\end{array}$ & 1,204 & 1,216 & 1,266 & 1,298 & 1,313 & 1,344 \\
\hline & limestone & 848 & 856 & 856 & 884 & 895 & 918 \\
\hline & TOTAL & 16,403 & 16,474 & 16,432 & 16,468 & 16,581 & 16,876 \\
\hline \multirow{8}{*}{ TECH } & steam coal & 10,253 & 9,597 & 9,283 & 8,959 & 8,729 & 8,484 \\
\hline & coking coal & 2,078 & 2,108 & 2,210 & 2,384 & 2,499 & 2,609 \\
\hline & $\begin{array}{c}\text { anthracite } \\
\text { coal }\end{array}$ & 340 & 325 & 322 & 330 & 328 & 327 \\
\hline & crude oil & 1,049 & 963 & 928 & 884 & 841 & 789 \\
\hline & LNG & 535 & 554 & 591 & 643 & 670 & 692 \\
\hline & $\begin{array}{l}\text { electric } \\
\text { poser }\end{array}$ & 1,196 & 1,144 & 1,180 & 1,199 & 1,194 & 1,186 \\
\hline & limestone & 842 & 805 & 798 & 817 & 814 & 810 \\
\hline & TOTAL & 16,293 & 15,495 & 15,312 & 15,215 & 15,075 & 14,898 \\
\hline \multirow{8}{*}{ СТАХ-90 } & steam coal & 10,253 & 9,539 & 9,163 & 8,748 & 8,590 & 8,358 \\
\hline & coking coal & 2,078 & 2,095 & 2,182 & 2,328 & 2,460 & 2,570 \\
\hline & $\begin{array}{c}\text { anthracite } \\
\text { coal }\end{array}$ & 340 & 323 & 318 & 322 & 323 & 322 \\
\hline & crude oil & 1,049 & 957 & 916 & 863 & 828 & 777 \\
\hline & LNG & 535 & 551 & 583 & 628 & 659 & 682 \\
\hline & $\begin{array}{c}\text { electric } \\
\text { poser }\end{array}$ & 1,196 & 1,137 & 1,164 & 1,171 & 1,175 & 1,169 \\
\hline & limestone & 842 & 800 & 787 & 798 & 801 & 798 \\
\hline & TOTAL & 16,293 & 15,401 & 15,114 & 14,858 & 14,835 & 14,676 \\
\hline \multirow{8}{*}{ TECH-90 } & steam coal & 10,253 & 9,100 & 8,640 & 8,198 & 7,969 & 7,656 \\
\hline & coking coal & 2,078 & 1,999 & 2,057 & 2,181 & 2,282 & 2,354 \\
\hline & $\begin{array}{c}\text { anthracite } \\
\text { coal }\end{array}$ & 340 & 308 & 300 & 302 & 300 & 295 \\
\hline & crude oil & 1,049 & 913 & 864 & 809 & 768 & 712 \\
\hline & LNG & 535 & 525 & 550 & 588 & 612 & 625 \\
\hline & $\begin{array}{c}\text { electric } \\
\text { poser }\end{array}$ & 1,196 & 1,085 & 1,098 & 1,097 & 1,090 & 1,071 \\
\hline & limestone & 842 & 764 & 742 & 747 & 743 & 731 \\
\hline & TOTAL & 16,293 & 14.694 & 14252 & 13,923 & 13,763 & 13,443 \\
\hline
\end{tabular}

million TC in 2005 to 36.12 million TC in 2030 for the BAU scenario. The TECH and CTAX cases show a slight decrease of iron ore consumption from the BAU values. These decreases are a result of technology replacement in the steel making process.

\section{3 $\mathrm{CO}_{2}$ Emissions}

Table 7 shows the $\mathrm{CO}_{2}$ emissions by fuel for different scenarios. In the case of coal, which is the highest emission fuel, the results from TECH and CTAX show an obvious decrease compared with that from BAU.

Fig. 10 illustrates the comparison of total emissions for each scenario. Total $\mathrm{CO}_{2}$ emissions based on BAU, increase from 16.4 million TC in 2005 to 16.9 million TC in 2030. In the TECH case, the emissions reduction relative to $\mathrm{BAU}$ ranges from $0.67 \%$ in 2005 to $11.72 \%$ in 2030. In the CTAX case, the imposition of 30 USD does not affect the TECH, and this means that the cost of 30 USD is not a

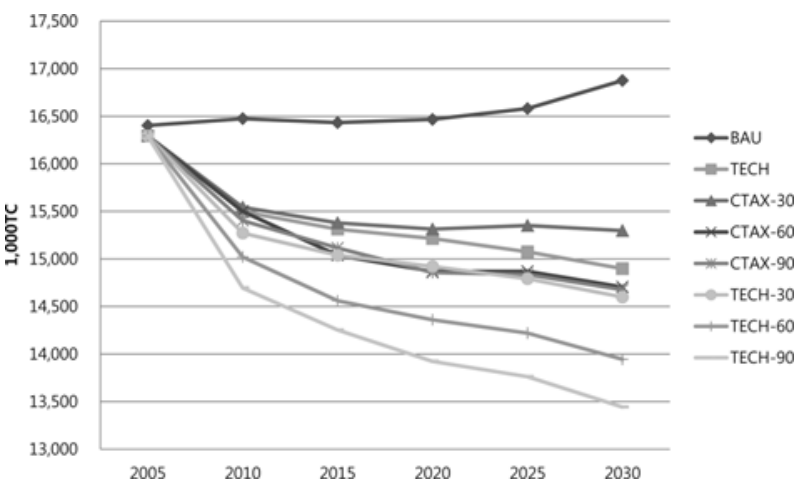

Fig. $10 \mathrm{CO}_{2}$ emissions forecast for different scenarios

significant level for $\mathrm{CO}_{2}$ emissions. This is because the iron and steel industry is a capital-intensive industry and uses the Make to Stock (MTS) production system based on forecasted demand. In the case of relatively high tax applications like CTAX-60 and CTAX-90, there is a very sensitive response for $\mathrm{CO}_{2}$ emissions. The $\mathrm{CO}_{2}$ emissions of CTAX-60 and CTAX-90 in comparison with BAU, decrease by $5.92 \%$ and $6.51 \%$, respectively, in 2010 and by $12.86 \%$ and $13.03 \%$, respectively, in 2030 .

\section{Conclusions}

This study presents the SD methodology to analyze the impact of the Convention on the Climate Change on the Korean steel industry. This paper demonstrates that $\mathrm{SD}$ is a suitable tool, by analyzing the reduction potential of $\mathrm{CO}_{2}$ emissions of this energy-intensive industry that is sensitive to environmental changes. The simulation model in this study is composed of five sub-modules. They include an iron and steel demand module, a material input module, an iron and steel-making module, an end-products production module, and a $\mathrm{CO}_{2}$ emissions module. In order to verify the validity of each model, back casting was performed. The back casting showed that all MAPEs were within the acceptable range, which justified the predictability of the model.

Three major scenarios are developed for analysis (the BAU scenario, the TECH scenario, and the carbon tax charge scenario). The FINEX process is considered independently in the TECH scenario. A carbon tax charge sensitivity analysis is performed for a range of carbon taxes ( $30 \$$ to $90 \$)$. The results of these experiments will likely contribute to the analysis of the future ramifications of how the Convention on Climate Change will impact the many energy-intensive industries.

In our paper, we applied the tax on the supply-side based on PPP standards. Currently carbon tax in Korea is discussed at a larger framework of environmentally friendly tax restructuring. Most of economists attest a supply-side is more effective in terms of PPP and convenience in collecting. We fully understand that we need to establish a general equilibrium scheme of model and tax scenario, including global carbon tax system and international competitiveness. However, this paper mainly attempts to find how a market-based carbon policy, tax policy, affects a behavioral change of an industry, steel industry, as a partial equilibrium case study in order to prepare a full scale carbon policy in Korea in the future of official burden sharing. Therefore, 
we try to focus on specific response of a certain industry under a market-based carbon policy. As the future research, we consider that we may be able to include rather more realistic assumptions and structure of modeling at the cost of parsimonious modeling

Secondly, the model is only focus on the first-order effect since the modeling frameworks is a type for partial analysis. We agree the reviewer's astute comment on the importance general equilibrium effect. This paper leavers a full scale modeling a further research.

Third, cap-and-trade is also a top candidate for a market-based carbon policy. However, this paper is focusing only on tax policy. The tax policy in Korea could be a pigouvian or not, depending on accurate estimation of damage function. We, however, believe that this paper attempt to analyzed an industry's behavior, as a cost-effective manner, though the tax rate is not a pigouvian, such as optimizing under the certain level of mitigation target.

\section{ACKNOWLEDGEMENT}

The present Research has been conducted by the Research Grant of Kwangwoon University in 2014.

\section{REFERENCES}

1. American Iron and Steel Institute, "Technology Roadmap Research Program for the Steel Industry,” No. DE-FC36-97ID13554, 2010.

2. Hidalgo, I., Szabo, L., Ciscar, C. J., and Soria, A., "Technological Prospects and $\mathrm{CO}_{2}$ Emission Trading Analyses in the Iron and Steel Industry: A Global Model," Energy, Vol. 30, No. 5, pp. 583-610, 2005.

3. International Energy Agency, "World Energy Outlook 2007," Renouf Pub. Co. Ltd., 2007.

4. Karavezyris, V., Timpe, K.-P., and Marzi, R., "Application of System Dynamics and Fuzzy Logic to Forecasting of Municipal Solid Waste," Mathematics and Computers in Simulation, Vol. 60, No. 3, pp. 149-158, 2002.

5. Kim, Y. and Worrell, E., "International Comparison of $\mathrm{CO}_{2}$ Emission Trends in the Iron and Steel Industry," Energy Policy, Vol. 30, No. 10, pp. 827-838, 2002.

6. Mashayekhi, A. N., "Transition in the New York State Solid Waste System: A Dynamic Analysis," System Dynamics Review, Vol. 9, No. 1, pp. 23-47, 1993.

7. POSCO, "The Finex Innovative Ironmaking Process," Proc. of the Asia-Pacific Partnership on Clean Development and Climate, 2008.

8. Ruth, M. and Amato, A., "Vintage Structure Dynamics and Climate Change Policies: The Case of US Iron and Steel," Energy Policy, Vol. 30, No. 7, pp. 541-552, 2002.

9. Siemens VAI Metals Technology, "SIMETAL Corex Technology," 2011.
10. Sterman, J. D., "Business Dynamics: Systems Thinking and Modeling for a Complex World,” Irwin/McGraw-Hill Boston, 2000.

11. Wang, K., Wang, C., Lu, X., and Chen, J., "Scenario Analysis on $\mathrm{CO}_{2}$ Emissions Reduction Potential in China's Iron and Steel Industry,” Energy Policy, Vol. 35, No. 4, pp. 2320-2335, 2007.

12. Worrell, E., Price, L., and Martin, N., "Energy Efficiency and Carbon Dioxide Emissions Reduction Opportunities in the US Iron and Steel Sector," Energy, Vol. 26, No. 5, pp. 513-536, 2001.

13. Yoon, H.-S., Lee, J.-Y., Kim, H.-S., Kim, M.-S., Kim, E.-S., et al., "A Comparison of Energy Consumption in Bulk Forming, Subtractive, and Additive Processes: Review and Case Study," Int. J. Precis. Eng. Manuf.-Green Tech., Vol. 1, No. 3, pp. 261-279, 2014.

14. Zhang, B., Wang, Z., Yin, J., and Su, L., " $\mathrm{CO}_{2}$ Emission Reduction within Chinese Iron \& Steel Industry: Practices, Determinants and Performance," Journal of Cleaner Production, Vol. 33, pp. 167-178, 2012. 